\title{
Recalling doctors back to Bhutan for COVID-19
}

\author{
Thinley Dorji1 ${ }^{1,2}$, Don Eliseo Lucero-Prisno III ${ }^{3}$
}

\section{AFFILIATION}

1 Department of Internal Medicine, Armed Forces Medical College, Maharashtra University of Health Sciences, Maharashtra, India

2 Kidu Mobile Medical Unit, His Majesty's People's Project, Thimphu, Bhutan 3 Department of Global Health and Development, London School of Hygiene and Tropical Medicine, London, United Kingdom

CORRESPONDENCE TO

Thinley Dorji. Department of Internal Medicine, Armed Forces Medical
College, Maharashtra University of Health Sciences, Pune, Maharashtra, India. E-mail: dorji.thinleydr@gmail.com ORCID ID: https://orcid. org/0000-0003-4932-8704

KEYWORDS

COVID-19, health services, human resources

Received: 30 July 2020, Accepted: 31 July 2020

https://doi.org/10.18332/popmed/125913

\section{Dear Editor,}

When the first case of COVID-19 in Bhutan was confirmed on 6 March $2020^{1}$, the country suddenly faced a real challenge that would test its healthcare system on many fronts. Bhutan, with a population of 0.7 million is a small landlocked country, with the high Himalayan mountains bordering China on one side and a porous border with India on the other. As the number of COVID-19 hotspots grew in many bordering Indian towns, many doctors were deployed for advocacy, surveillance and clinical monitoring in the bordering districts $^{2}$. At the same time, more than 8700 Bhutanese were repatriated from India, South-East Asia, Middle East and the Americas and kept in quarantine facilities for 21 days with daily monitoring and evaluations by doctors ${ }^{2}$. With only 326 (total 376) doctors in the country ${ }^{3}$, this resulted in the worsening of the chronic shortage of doctors. The country needed a strategy to address this.

Bhutan is one of the few countries that do not have a medical school. The Khesar Gyalpo University provides postgraduate medical courses and specialised training in selected clinical fields. A significant number are still trained in Thailand, India, Bangladesh, Nepal, and Malaysia. Fifty doctors (13.3\% of total registered in the country) are in these countries undergoing postgraduate studies in medicine, surgery, orthopaedic surgery, pathology, radiology, psychiatry, interventional cardiology, oncosurgery, and neurosurgery. The Royal Government of Bhutan in March 2020 took a decisive action to recall all these doctors to address this acute shortage of doctors thus cutting their training programs.

After repatriation, these doctors were placed in key geographical locations to relieve other doctors for COVID-19 case management, population surveillance, monitoring of quarantine facilities, and development of local COVID-19 guidelines on top of providing uninterrupted routine care services. With the closure of the international border, referral of patients to India for therapies and procedures not available in the country were stopped. Some of these postgraduate doctors suddenly performed pioneering procedures in the country including cardiac pacemaker implantation ${ }^{4}$. However, having interrupted the postgraduate training, some of these doctors might have their courses prolonged, with the country possibly incurring additional costs for their training.

COVID-19 is a wake-up challenge for the country to finally address the issue of shortage among its healthcare workforce. Policymakers and implementers need to fasttrack its roadmap towards the achievement of Universal Health Care and improvement of tertiary care through strengthening its human resources for health.

\section{REFERENCES}

1. LeVine S, Dhakal GP, Penjor T, et al. Case Report: The First Case of Novel Coronavirus Disease (COVID-19) in Bhutan. Am J Trop Med Hyg. 2020;120(6):1205-1207. doi:10.4269/ajtmh.20-0259

2. Ministry of Health. COVID-19 UPDATES: National Situational Report. http://www.moh.gov.bt/page/2/. Accessed July 12, 2020.

3. Ministry of Health. Annual Health Bulletin 2020. Thimphu: Ministry of Health, Royal Government of Bhutan; 2020. http:// www.moh.gov.bt/wp-content/uploads/ict-files/2017/06/ health-bulletin-Website_Final.pdf. Accessed July 30, 2020. 
4. Tshedup Y. First local independent pacemaker surgery successful. https://kuenselonline.com/first-local-independentpacemaker-surgery-successful/?fbclid=IwAR08YS2-V3jHAH paaZt6Fu7fT780K094Rq0LfDgnpTZKw0Gq2YXGjXaPoC0.

Published July 4, 2020. Accessed July 30, 2020. 